\title{
BIOCOLLOIDS OF URINE IN HEALTH AND IN CALCULOUS \\ DISEASE. III. THE MUCOPROTEIN MATRIX OF URINARY CALCULI ${ }^{1}$
}

\author{
By WILLIAM H. BOYCE AND NORMAN M. SULKIN \\ (From the Departments of Urology and Anatomy, Bowman Gray School of Medicine of Wake \\ Forest College, Winston-Salem, N. C.)
}

(Submitted for publication March 19, 1956; accepted May 24, 1956)

Over a period of three years 676 renal or ureteral calculi have been decalcified by chelating agents. The matrix has been recovered by ultrafiltration through collodion membranes and subjected to analysis by a variety of techniques. The present report is concerned with the microscopic structure and the histochemical properties of the matrix recovered from calcigerous stones.

\section{MATERIAL AND METHODS}

Preparation of matrix for histochemical studies. The decalcifying solution contained 5 per cent $(\mathrm{wt} / \mathrm{v})$ tetrasodium ethylenediaminetetraacetate and 10 per cent (v/v) formalin adjusted to $\mathrm{pH} 7.8 \pm 0.1$ with $12 \mathrm{~N} \mathrm{HCl}$.

Sixty-four calcigerous stones of wet weight $60 \mathrm{mg}$. to $28.35 \mathrm{gm}$., when surgically removed from the renal pelvis or ureter, were immediately rinsed in water and bisected with a hacksaw. The two halves were placed in a stoppered Erlenmeyer flask containing $500 \mathrm{ml}$. of decalcifying solution. The filings from the sawcut were subjected to chemical (1) and spectroscopic (2) analyses.

The flasks containing the halved calculi were carefully stored at $3^{\circ} \mathrm{C}$. and every effort was made to prevent agitation of the solution. At 7 to 10-day intervals the decalcifying solution was removed by pipette and filtered through collodion membranes of 0.01 micron in pore size. $^{3}$ Refiltration through membranes of average pore diameter less than 0.005 micron did not result in recovery of additional material. The decalcifying solution was carefully replaced and the process continued for 3 to 27 weeks, depending upon the size of the stone and the rate of decalcification. The residual matrix invariably formed a complete cast of the original stone, and decalcification of a degree permitting sectioning with the

1 This investigation was supported by research grants A-259 from The National Institute of Arthritis and Metabolic Diseases, and B-342 from The National Institute of Neurological Diseases and Blindness, National Institutes of Health, Department of Health, Education, and Welfare, and by a grant-in-aid from the Squibb Institute for Medical Research, New Brunswick, New Jersey.

3 Schleicher \& Schuell Co., Kenne, N. H., "S \& S Ultrafine Filters" the porosity of which has been checked by electronmicroscopy. microtome was evidenced by translucence when a light was held beneath the flask. In many instances no gross evidence of decalcification was observed until the entire "stone" was found floating on the surface of the solution.

Only a very minute amount of material was recovered from the ultrafiltration of the decalcifying solution through collodion membranes. This was recovered by ethanolether dissolution of the membranes at minus $5^{\circ} \mathrm{C}$, and the mucoprotein precipitate was concentrated by centrifugation. After dehydration and embedding, this material was sectioned and treated in the same manner as the residual matrix.

When decalcification was complete the matrix was gently floated into smaller containers, dehydrated and embedded in the manner usually employed for microscopic study of tissues. Serial sections 8 to 10 microns in thickness were taken at intervals through the matrix of each calculus. Representative sections from each specimen were then treated according to the techniques described below.

Three calculi in this group of 64 formalin fixed stones had a centrally calcified core with an enveloping surface of laminated organic material 4 to $12 \mathrm{~mm}$. in thickness (Figure 1). A portion of this surface material was cut away, fixed in formalin, sectioned with the microtome, and treated by the methods described below. These calculi, with most of the roentgenolucent cover intact, were then decalcified and subsequently studied in the same manner as all other calculi in the series. The 24-hour urinary calcium excretion in each of these patients was less than $36 \mathrm{mg}$. on three or more determinations. This surface material was therefore considered to represent matrix that had not been calcified, and is subsequently referred to as uncalcified matrix in contradistinction to matrix which refers to the organic residue recovered by decalcification.

Hematoxylin and eosin. The acid hematoxylin eosin technique was employed in the same manner as for tissue staining (3, p. 114).

Periodic acid Schiff reaction. The McManus-Hotchkiss technique as described by (Lillie 3, p. 120-128) was utilized. Glycogen was removed from control sections by incubation in a buffered solution of 1 per cent malt diastase for one hour at $37^{\circ} \mathrm{C}$. The sections were mounted on slides and impregnated with collodion. They were then treated with 1 per cent periodic acid for 10 minutes, stained in the Schiff reagent for 15 minutes and rinsed in sulphurous acid. For purposes of orientation, other sec- 

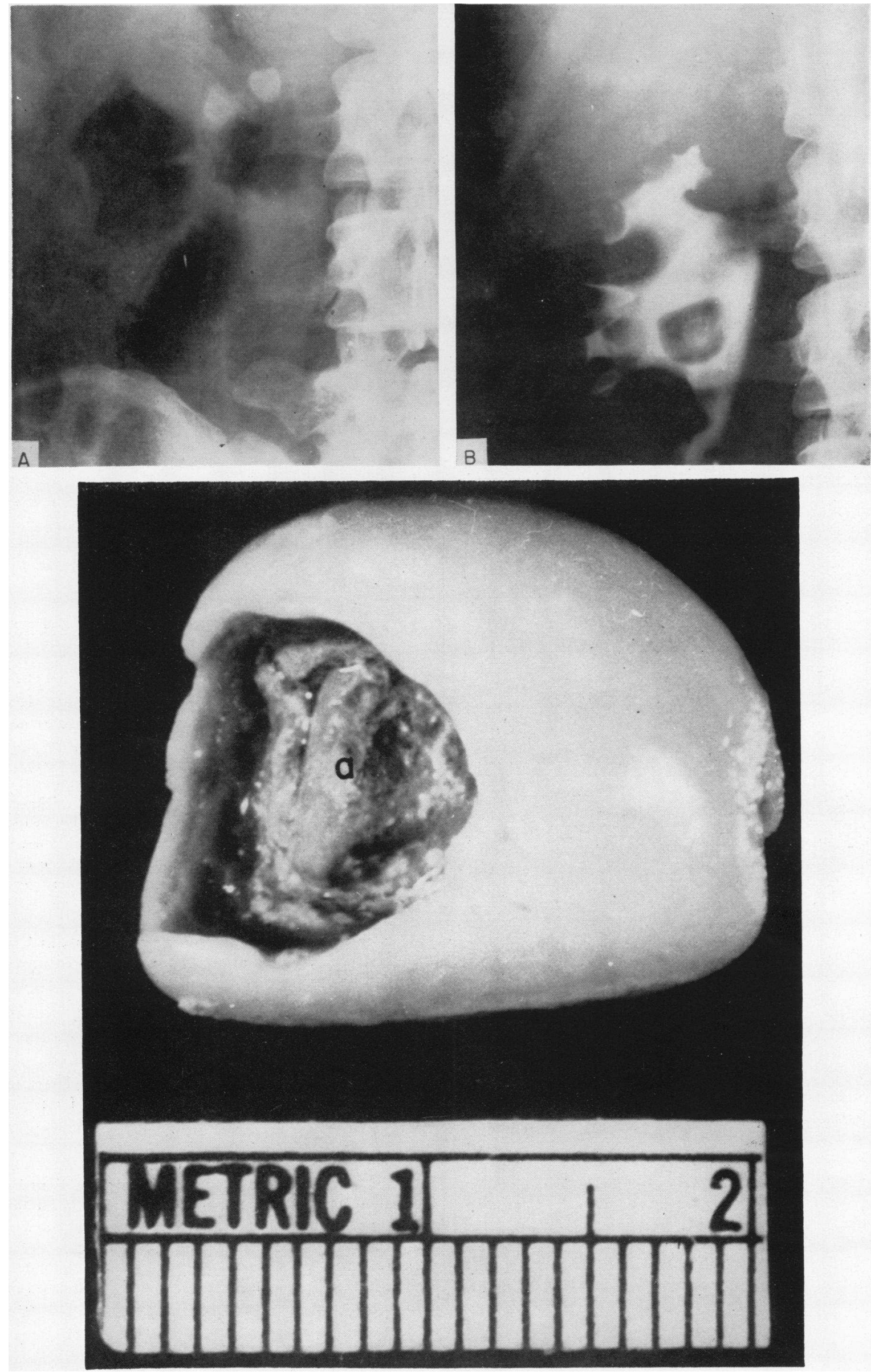

FIG. 1.

1068 
tions were studied by counterstaining with acid iron hematoxylin (Weigert's), and also without the preliminary incubation with diastase.

Aqueous toluidine blue. Holmgren's (4) technique for staining with 0.25 per cent aqueous solution of recrystallized toluidine blue was utilized. Comparable sections were also treated with concentrated sulphuric acid by previously described modifications of the Kramer-Windrum method (5). These sections were then stained with toluidine blue as above.

Sudan black. Paraffin sections were treated with sudan black and were mounted in glycerin jelly in order to determine whether the PAS positive reaction was due to the presence of partially oxidized lipids.

In addition to the above studies, sections from representative calcium oxalate, calcium phosphate, and mixed calcigerous stones, including those with magnesium ammonium phosphate, were stained with the von Kossa technique $(3$, p. 264), utilizing either safranin or PAS counterstain. Mayer's mucihematein and mucicarmine stains $(3$, p. 286) were also applied to sections from these calculi.

Matrix content of calculi. The halves of 264 freshly recovered calculi were grouped into four types of pools on the basis of chemical composition of the crystalline components. Pools of calcium phosphate, calcium oxalate, mixed calcium oxalate and phosphate, and mixed calculi containing magnesium ammonium phosphate were thus formed. The individual pools containing 25 to 100 calculi each were dried over "Drierite" in a vacuum desiccator at $20 \mathrm{C}$ to constant weight. The final weight of the pools varied between 25.23 and $68.45 \mathrm{gm}$. The dried calculi were then decalcified by continuous agitation in 5 per cent ethylenediaminetetraacetate adjusted to $\mathrm{pH} 7.8$, but without the addition of formalin. The solution was dialyzed against distilled water and ultrafiltered through collodion membranes. The matrix thus recovered was again dialyzed against distilled water and lyophilized. This matrix was dried in vacuo to constant weight and the percentage composition of the calculi determined.

Preparation of matrix for chemical analyses. Lyophilized matrix from the above pools was subjected to elemental analyses. Matrix from similar pools of 348 freshly recovered calculi which were not dehydrated were analyzed for protein and carbohydrate content. The Molisch and anthrone tests were performed as described by Dische (6). The orcinol (protein bound hexoses) and diphenylamine (sialic acid) tests were done as described by Winzler (7). The diphenylamine test was also applied by the method of Anderson and Maclagan (8) with control studies on urinary mucoprotein isolated by the techniques of these authors. The Hale test for acid mucopolysaccharides was performed by the method of $\mathrm{Di}$ Ferrante (9). The ninhydrin and biuret tests were made by standard techniques (10). Tests for hexuronic acids were made by the naphthoresorcinol (11) and carbazole (12) methods. Hexosamines were determined by both the Elson-Morgan (7) and indol- $\mathrm{HCl}$ (6) reactions. Control tests were made with standard solutions of human serum proteins, serum glycoproteins, hexoses, glucuronic, and galacturonic acid.

The elemental analyses of the lyophilized matrix were made by standard techniques (13). Analyses for carbon and hydrogen were by the universal tube filling method. Nitrogen determinations were by the Dumas procedure, and total phosphorus and sulphur determinations were by gravimetric analyses following a Carius wet digestion. The conjugated sulfates were determined by first precipitating the inorganic sulfates with barium chloride, followed by hydrolysis of the organic material in $2.4 \mathrm{~N}$ $\mathrm{HCl}$ for 3 hours and determination of the liberated sulfate by the method of Folin (14). The inorganic ash was determined by igniting the material in the presence of an excess of sulphuric acid.

\section{RESULTS}

\section{Microscopic structure}

The crystalline composition of the formalin fixed calculi was mixed calcium oxalate and calcium phosphate in 26 , calcium oxalate in 18 , calcium phosphate in 12, and calcium phosphate with magnesium ammonium phosphate in 8 . It was not possible to detect any structural or histochemical characteristics of the matrix which could be correlated with the crystalline composition of any of these calculi, hence the following descriptions apply to any calculus in the series.

The organic matrix was uniformly distributed from the center to the surface of all calculi (Figure 2). The matrix was composed of broad bands of parallel fibers with an amorphous interfibrillar material. These bands had a tendency to form circular whorls so that a single section usually presented some of the bands with the long axes of the fibers parallel to the plane of section and others at right angles (Figure 3). The physical characteristics of the calculus were definitely related to the structure of the matrix. Smooth surfaced calculi were found to exhibit broad bands of parallel fibers with little tendency to small whorls (Figure 3-A and $\mathrm{C}$ ). The calculi with nodular surfaces presented small compact circular whorls of matrix

Fig. 1. Renal Calclli with Calcified Centers and Covering layer of Uncalcified Matrix

A. Plain roentgenogram showing two calcific densities within the right renal pelvis.

B. Retrograde pyelogram demonstrating the radiolucent uncalcified matrix.

C. Calculus sectioned to show the calcified center (a) and the laminated uncalcified matrix. 

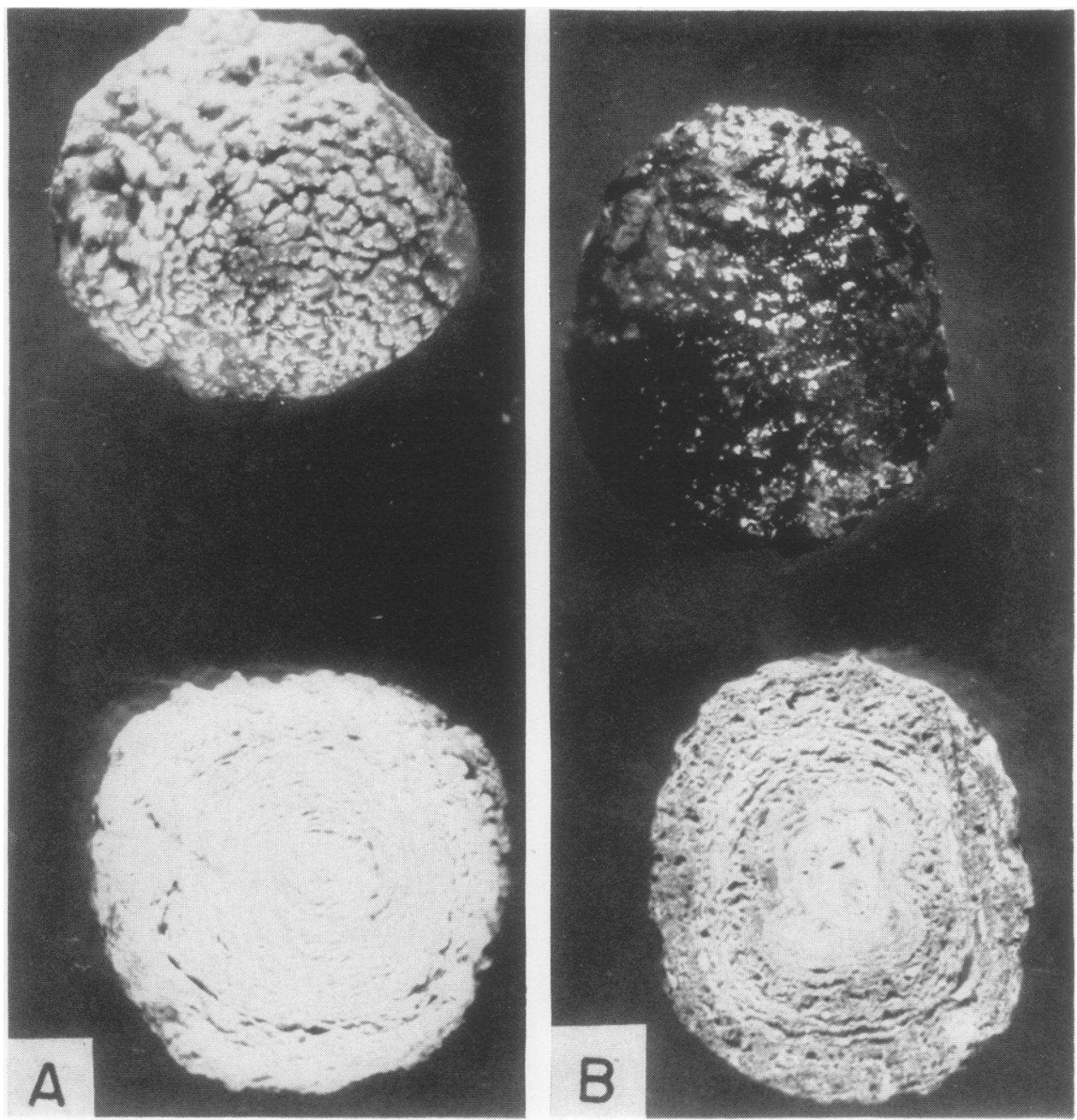

Fig. 2. Mixed Calcium Phosphate and Oxalate Renal Calculus

A. Surface and center section of unstained calculus.

B. Surface and center section from opposite half of same calculus treated with aqueous toluidine blue. Note distribution of stained organic material throughout the calculus and on the surface. Several "nuclei" are visible near the center of the calculus.

fibers which formed a single nodule (Figure 3-B). Broad bands and small whorls of fibers were encountered at any level from center to surface of the various calculi. Sections through the central "core" of partially decalcified stones revealed only a small compact whorl of matrix and inorganic crystals (Figure 6-A). In no instance was there evidence of a nidus of cellular debris, bacteria, or other foreign material. Cross sections of many calculi revealed multiple "nuclei" (Figure 2-B) which were found to be compact whorls of organic matrix (Figure 3-B).

Between the fibrils a variable quantity of amorphous material was found in all specimens.
This was most abundant in surface layers of uncalcified matrix in which the fibrillar structure was not as well developed as in the decalcified matrix (Figure 5). The material which diffused into the solution from the decalcifying process, and which was recovered on the collodion membranes of the ultrafilter, was composed entirely of this amorphous substance.

Cellular elements were abundant within the body of many calculi and were occasionally seen in the surface layers of the matrix (Figure 4). Segmented polymorphonuclear leukocytes, monocytes, and eosinophils were present in the inner layers of some calculi (Figure 3-A). Sheets of 
lymphocytes were rarely encountered, but sometimes occurred in such numbers as to suggest a "lymphocytic stroma" in small areas of the calculus (Figure 4-A). The most uniformly present and most abundant cells encountered in the entire series were bundles of smooth muscle. These appeared to be viable cells encountered sporadically from the deepest to the most superficial layers of the calculi. These cells were often associated with fibroblasts, capillaries, and a few large cells which appeared to be transitional epithelium but occasionally resembled "foam cells". Approximately one-third of the specimens examined showed cellular elements to be present in some of the sections. Bacteria were observed in only 10 per cent of the specimens. These cellular elements were so ir-
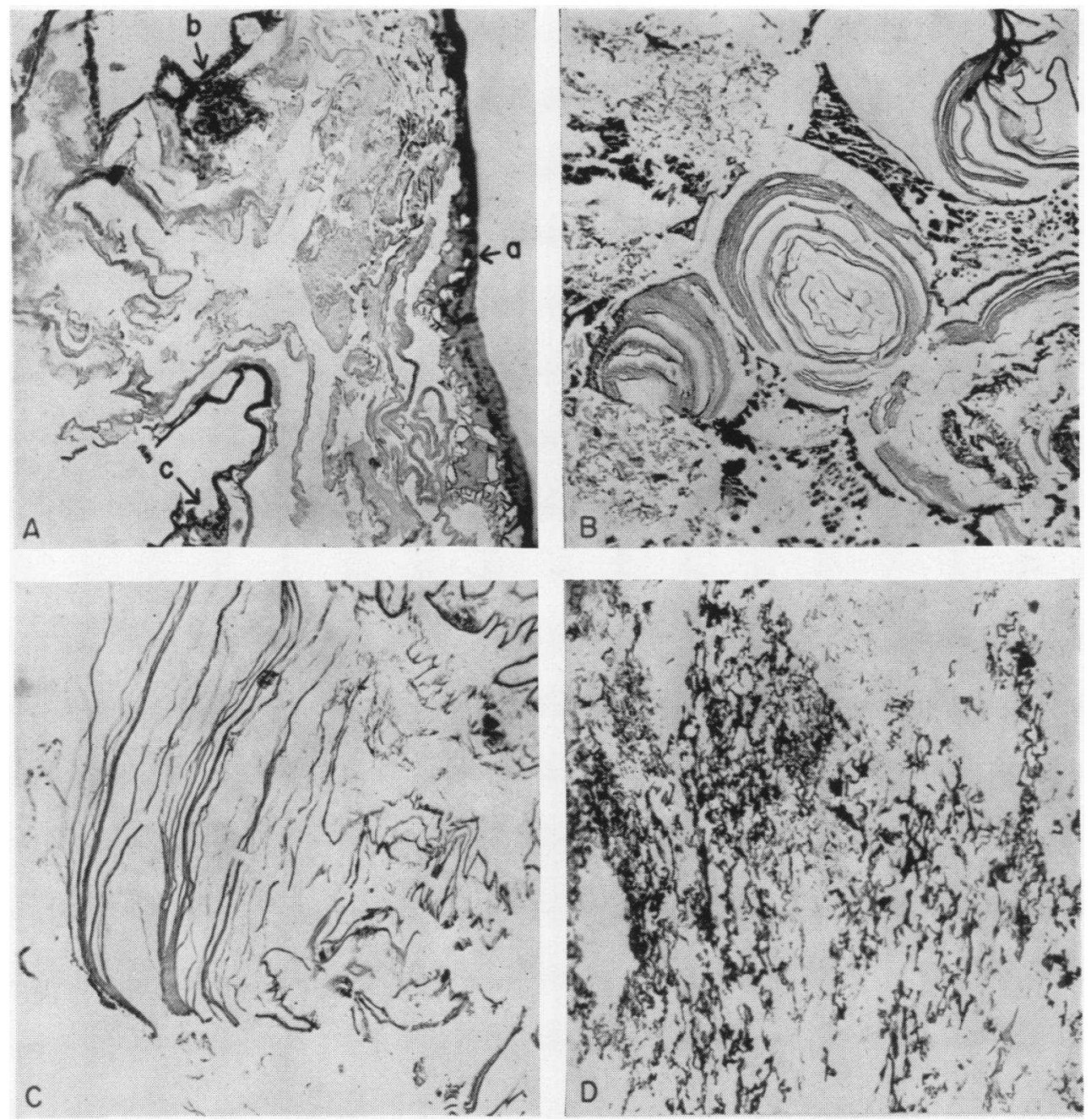

Fig. 3. Photomicrographs of Decalcified Renal Calculi

A. Section of matrix from calcium phosphate calculus stained with hematoxylin and eosin, $10 \times$ ocular and $10 \times$ objective. Surface layer of matrix (a) contains a few epithelial cells, and body of calculus contains cellular elements ( $b$ and $c$ ).

B. Section from center of calculus in Figure 2, $10 \times$ ocular and $10 \times$ objective. Mucicarmine, iron-hematoxylin, metanil yellow treatment stains matrix red and residual inorganic crystals a deep violet.

C. Section of decalcified matrix from pure calcium phosphate calculus treated by periodic acid Schiff sulfite leucofuchsin method, $10 \times$ ocular and $10 \times$ objective.

D. Section of decalcified matrix from mixed calcium phosphate and oxalate calculus treated by periodic acid Schiff sulfite leucofuchsin method, $10 \times$ ocular and $10 \times$ objective. 
regularly distributed in the various calculi, and were absent in so many of the sections, that they were considered to represent elements of granulation tissue which had extended into the interstices of the calculi and thus were probably secondary to the inflammatory reaction produced by the stone or associated infection. The well preserved structural and staining characteristics of these cellular elements inclicates that the technique of decalcification, fixation, sectioning, and staining of the stone was not so severe as to disrupt the organic structure to any great extent.

Hematorylin and cosin stain. Both the fibrils and the amorphous material of the matrix stained faintly with eosin. No histochemical importance is attached to these stains which are primarily designed to delineate the cellular elements, bacteria, and structural characteristics of the matrix.

Periodic acid Schiff and sulfite leucofuchsin reactions. The entire matrix of all calculi was colored a brilliant purplish-red with this technique (Figures 5-A and B). The fibrils appeared to stain more brilliantly and a deeper red than did the amorphous interfibrillar material, but both were strongly PAS positive. No difference in this reaction was noted between those sections sub-
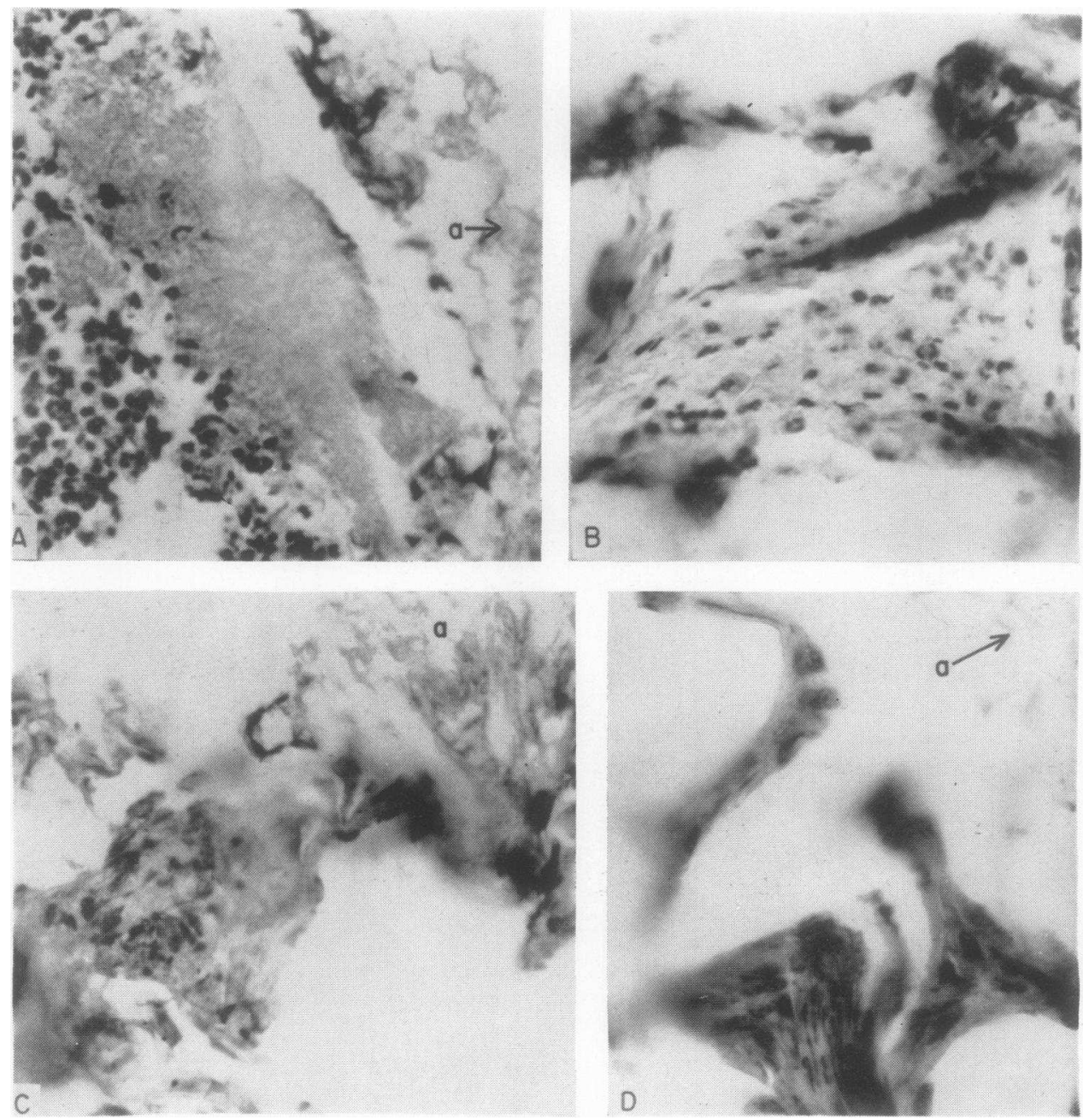

Fig. 4. Cellullar Elements Encountered within the Bodies of Various Calculi

All sections stained with hematoxylin and eosin, $10 \times$ ocular and $44 \times$ objective. Smooth muscle, fibroblasts, lymphocytes and monocytes are visible. Transitional epithelial cells appear in some areas and unidentified "foam cells" were seen in some sections. Matrix (a) stains very faintly pink with eosin. 


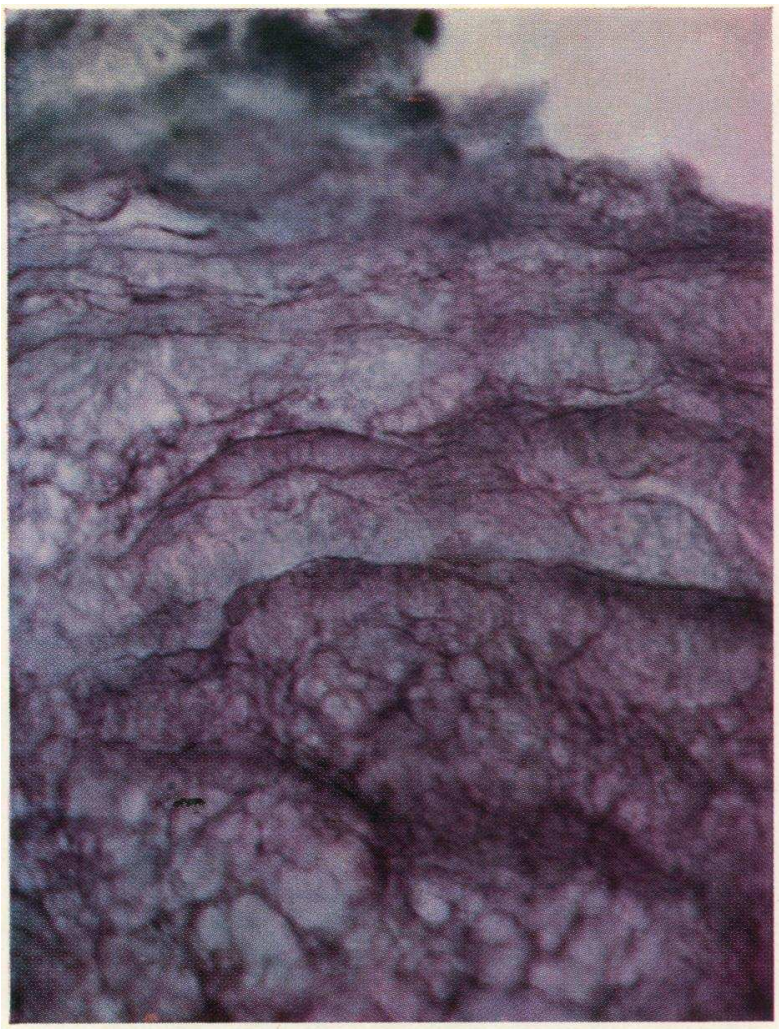

A

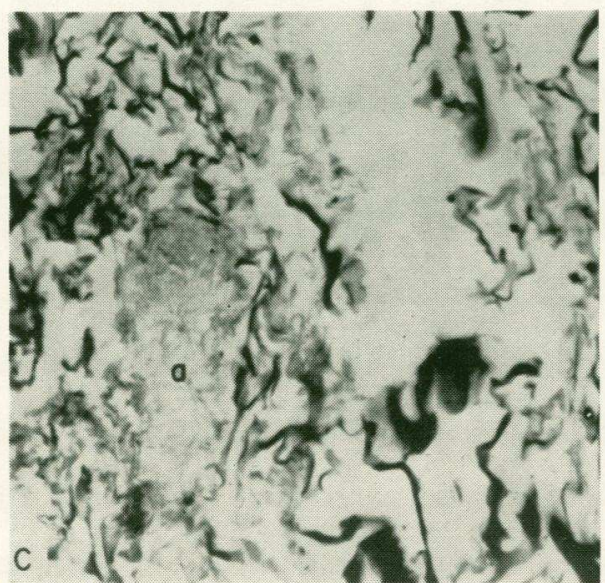

Fig. 5. Metachromasia in Calculous Matrix

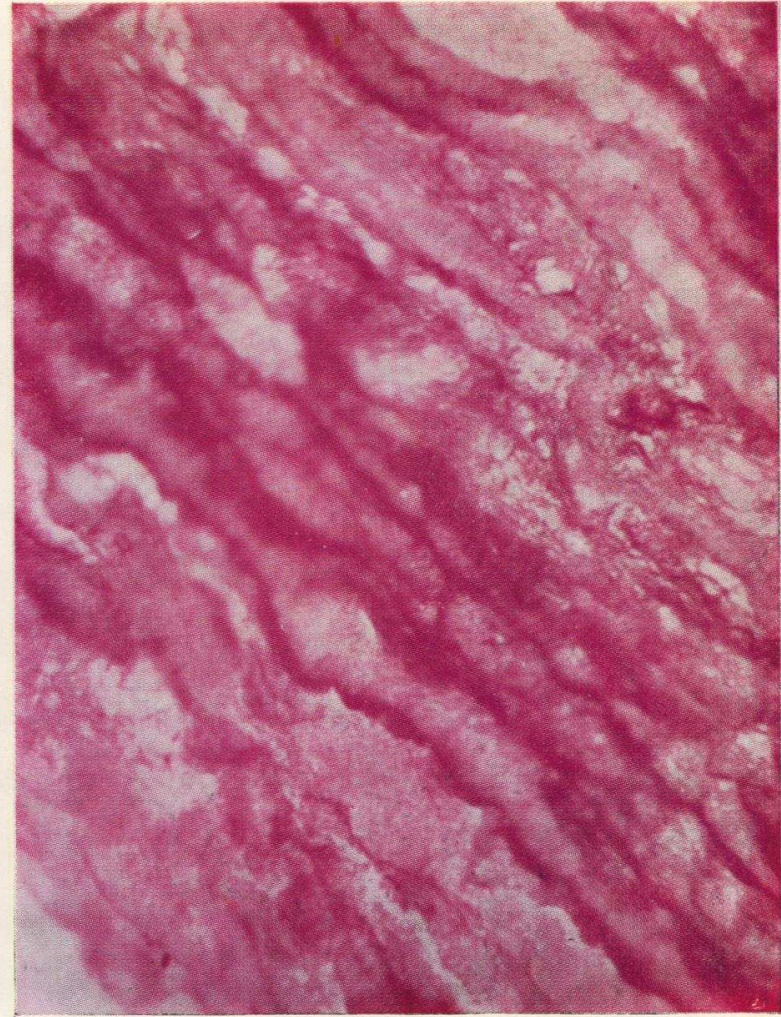

B

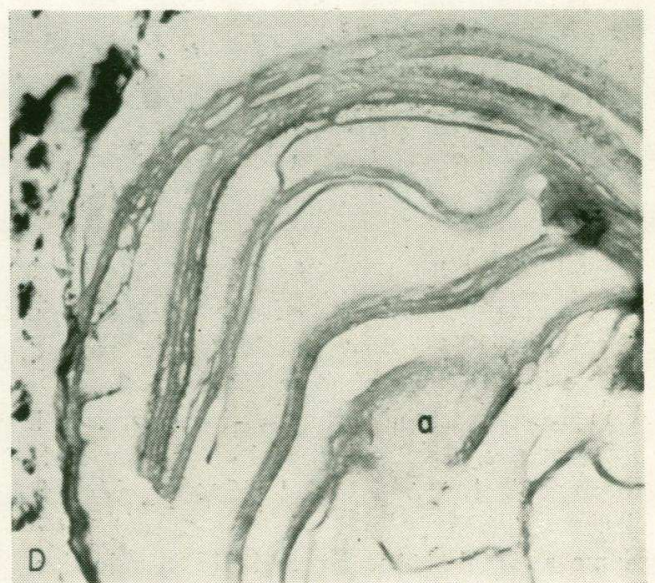

A. Section of uncalcified matrix from calculus in Figure $1,10 \times$ ocular and $44 \times$ objective. Light areas (a) stain intense purplish-red, dark staining fibrils are orthochromatic with aqueous toluidine blue.

B. Section corresponding to A treated with the periodic acid Schiff sulfite leucofuchsin technique.

C. Decalcified matrix from calcium oxalate calculus stained with toluidine blue, $10 \times$ ocular and $44 \times$ objective. Most of the matrix is orthochromatic but areas of metachromasia (a) are present.

D. Decalcified matrix from calcium phosphate calculus stained with toluidine blue, $10 \times$ ocular and $44 \times$ objective. Most of the matrix is orthochromatic but areas of metachromasia (a) are present. 

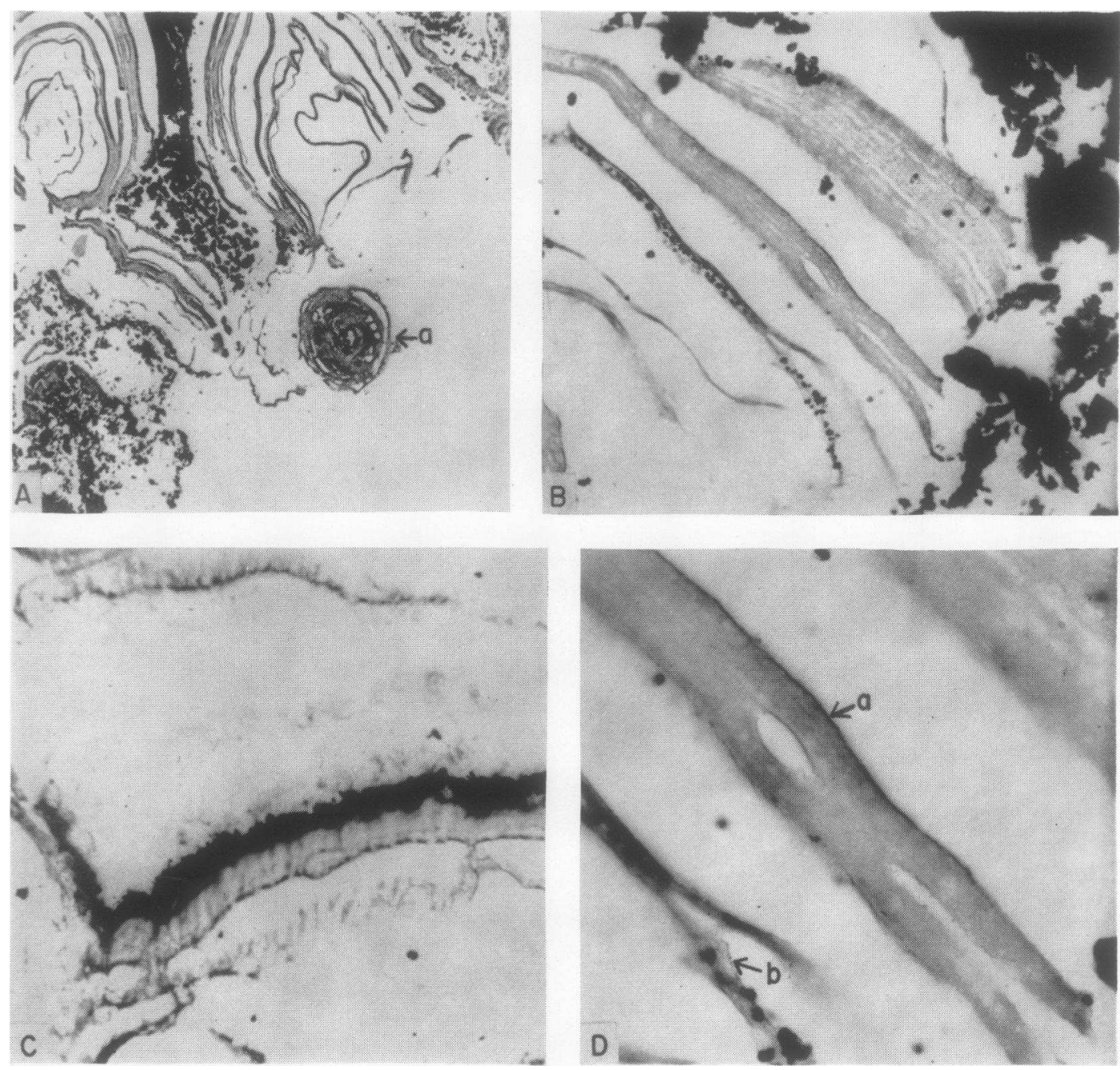

Fig. 6. Distribution of Inorganic Crystals in Partially Decalcified Calculi

A. Von Kossa method with safranin counter stain through the center of mixed calcium phosphate and oxalate calculus, $10 \times$ ocular and $10 \times$ objective. Small spherule of matrix and crystals (a) may be the initial stage in formation of some calculi.

B. Von Kossa method with mucicarmine, iron-hematoxylin, metanil yellow counter stain of section from calcium phosphate calculus, $10 \times$ ocular and $44 \times$ objective.

C. Same as A, $10 \times$ ocular and $115 \times$ objective, to show distribution of crystals (black) along margins of fibrils.

D. Same as B, $10 \times$ ocular and $115 \times$ objective. Marginal silver deposits (a) may represent binding of silver ions by organic groups rather than inorganic phosphates. Amorphous material surrounding crystalline deposit is shown at (b).

jected to diastase treatment as compared with the control sections, indicating that the positive reaction is not due to the presence of glycogen. Weigert's acid iron hematoxylin counterstain obscured the PAS reaction in many areas of all sections, but there was no uptake of the hematoxylin stain by the matrix.

Toluidine blue. The matrix of all stones stained uniformly and deeply orthochromatically blue. However, there were areas of varying degree of metachromasia in every stone regardless of the crystalline composition (Figure 5). This confirms the observations reported by Howard (15) for phosphatic calculi. In our experience oxalate calculi also contain some metachromasia if the matrix is serially sectioned. 
The uncalcified matrix demonstrated a very deep purplish-red metachromasia involving especially the peri-fibrillar areas (Figure 5-A). This metachromasia appeared to be enhanced by prolonged treatment of the uncalcified matrix through the decalcifying process, hence processing of the calcified stones did not destroy the metachromatic properties of the matrix.

Treatment of the matrix in concentrated sulfuric acid resulted in an increase in the metachromatic properties of the decalcified matrix. This was attributed to sulfation of the PAS positive mucoprotein (5) rather than to the removal of additional cationic groups since a reducing acid rinse was utilized prior to the PAS treatment of control sections.

von Kossa stain for "calcium salts." This test depends upon the presence of insoluble substances which can bind silver ions in such a manner that after exposure to sunlight they can subsequently be reduced by developer and the unbound silver cleared with thiosulfate in the same manner as photographic emulsions. The insoluble phosphates, alkali salts of fatty acids, and free aldehyde groups of large molecules may give positive results with the stain. The large crystalline de. posits (Figure 6) which give the von Kossa stain are considered to be calcium phosphate crystals because the inorganic ash of these preparations is composed almost entirely of calcium phosphate, and because the same deposits stain a deep blue with alum hematoxylin and grey-violet with iron hematoxylin in corresponding sections. The thin line of reduced silver along the margins of the fibrils (Figure 6-D) may not be phosphate crystals, but may represent free aldehyde or other groupings capable of binding silver ions.

The black deposits of "calcium salts" were found to occur in linear arrangements along the borders of the fibrillar matrix and appeared to be intermingled with the amorphous interfibrillar portions of the matrix (Figure 6-C).

Stains for mucin. Treatment with the mucicarmine, iron hematoxylin, metanil yellow stain of Mayer resulted in a diffuse red color in the matrix. It was noted that incompletely decalcified matrix demonstrated a tendency to stain yellow along the borders of fibrils where calcium salts were deposited (Figure 6-D). Mucihematein stained the entire matrix a diffuse light violet.
Tests for lipids. No specimen demonstrated any indication of lipid soluble staining with $\mathrm{Su}$ dan black. This was interpreted as evidence that the PAS positive substance was not partially oxidized lipid such as lipofuscin or "ceroid." In addition to these studies, which were made on sections from all specimens, the lyophilized matrix from pooled calculi was tested for the presence of lipids with osmic acid and by the Wilson-Hanner method for determination of serum lipids (16). No evidence of free or protein bound lipids could be detected in any of the specimens.

\section{Chemical studies of stone matrix}

The quantity of matrix recovered from the various types of crystalline calculi is presented (Table I). The matrix, as recovered from the decalcifying solution, contained 5.22 to 14.98 per cent of inorganic ash as determined by ignition of the material in the presence of sulphuric acid. The cationic component of the ash was calcium with only traces of magnesium. The major anionic component was phosphate. The ash is expressed therefore as largely calcium phosphate with the excess of calcium as the sulfate. The average quantity of ash-free matrix in all calculi was 2.52 gm. per $100 \mathrm{gm}$. of dry calculus.

It was observed that between 40 and 60 per cent of the lyophilized stone matrix, which had not been fixed in formalin, was soluble in molar sodium chloride by repeated extractions. The soluble and insoluble forms of the matrix were recovered by relyophilization and subjected to the same studies as the total matrix. Microscopic sections revealed the soluble material to be composed entirely of the amorphous portions of the matrix, and the insoluble material to be composed largely of the fibrillar material. These two fractions of the matrix revealed entirely similar histochemical reactions to all of the above tests with the exception that metachromasia with toluidine blue was occasionally demonstrated in the soluble amorphous material but not in the fibrillar residue.

It was observed that the soluble portion of the stone matrix was electrophoretically homogeneous and retained a net negative charge (migrated toward the anode) at $\mathrm{pH} 4.5,8.6$, and 12.0. The electrophoretic mobility at $\mathrm{pH} 8.6$ in veronal buffer of ionic strength 0.1 was $-5.61 \times 10^{-5} \mathrm{~cm}^{2}{ }^{2}$ 
TABLE I

A mount of lyophilized matrix recovered from calcigerous urinary calculi

\begin{tabular}{|c|c|c|c|c|c|}
\hline \multirow[b]{2}{*}{ Type of calculi } & \multicolumn{3}{|c|}{ Weight } & \multicolumn{2}{|c|}{ Corrected amount of } \\
\hline & $\begin{array}{l}\text { Dry } \\
\text { stones } \\
(\mathrm{gm.})\end{array}$ & $\underset{(g m .)}{\text { Matrix }}$ & Per cent & $\begin{array}{l}\text { Inorganic ash } \\
\text { in matrix } \\
\text { (per cent) }\end{array}$ & $\begin{array}{l}\text { Matrix } \\
\text { in stones } \\
\text { (per cent) }\end{array}$ \\
\hline $\begin{array}{l}\text { Pool No. 1, } 100 \text { stones-mixed } \\
\text { Ca-oxalate and Ca-phosphate }\end{array}$ & 68.45 & 2.2041 & 3.22 & 12.46 & 2.82 \\
\hline $\begin{array}{l}\text { Pool No. 2, } 50 \text { stones-Calcium } \\
\text { phosphate }\end{array}$ & 40.24 & 1.0001 & 2.48 & 6.84 & 2.32 \\
\hline $\begin{array}{l}\text { Pool No. 3, } 25 \text { stones-Ca-phos- } \\
\text { phate and } \mathrm{Mg}-\mathrm{NH}_{4} \text { phosphate }\end{array}$ & 35.84 & 0.7526 & 2.10 & 5.22 & 2.00 \\
\hline $\begin{array}{l}\text { Pool No. } 4,88 \text { stones-Calcium } \\
\text { oxalate }\end{array}$ & 35.19 & 1.3358 & 3.79 & 14.98 & 3.22 \\
\hline $\begin{array}{l}\text { Pool No. } 5 \text {, single calculus, Ca- } \\
\text { phosphate and } \mathrm{Mg}-\mathrm{NH}_{4} \text { phos- } \\
\text { phate }\end{array}$ & 25.23 & 0.5940 & 2.35 & 5.37 & 2.23 \\
\hline Total & 204.95 & 5.8866 & 2.79 & 8.97 & 2.52 \\
\hline
\end{tabular}

volt per sec. under a potential gradient of 6.6 volt per $\mathrm{cm}$. for a duration of $7,200 \mathrm{sec}$.

Elemental analyses of the matrix. Table II is a compilation of the average elemental composition of matrix recovered from five pools of calculi. The analysis of the total matrix is compared with that of the molar sodium chloride soluble and insoluble fractions of the same pools. These results have been corrected for inorganic ash content.

Spectroscopic analysis of the ash revealed calcium and phosphorus to be the predominant elements, although traces of magnesium were usually present. The inorganic ash from lyophilized matrix was analyzed for calcium content. The amount of calcium in the matrix from the 5 pools of calculi varied between 0.56 and 4.49 per cent (wt/ wt). The amount of calcium in the ash from lyophilized matrix obtained from 5 pools of calculi exceeded the amount of $\mathrm{Ca}_{3}\left(\mathrm{PO}_{4}\right)_{2}$ as calculated from the total phosphorus present in every sample. This "excess" calcium accounted for 0.19 to 0.64 per cent of the total matrix.

Tests for protein. The biuret, ninhydrin, xanthoproteic and Millon tests were all positive for both the sodium chloride soluble and insoluble portions of the matrices. When human serum albumin was utilized as a standard the biuret test indicated a protein content of 68 to 73 per cent for 5 determinations of total matrix. The ninhydrin reaction was much more pronounced after hydrolysis, indicating an increase in free amino groups and suggesting the possibility that hexosamine may be present as $\mathrm{N}$-acetyl-hexosamine.

General tests for carbohydrates in total matrix. The anthrone test produced a blue color with absorption maximum at $625 \mathrm{~m} \mu$. The Molisch test also gave a positive reaction with peak absorption at $570 \mathrm{~m} \mu$. The orcinol test gave a brown to yellow color with absorption maxima at 420 and $540 \mathrm{~m} \mu$, indicating the presence of hexoses other than hexosamine. The hexose content of total matrix from 5 pools of calculi varied between 10.6 and 15.3 per cent with a mean value of 13.6 per cent. The Di Ferrante test was faintly positive, but this method for the detection of acid polysaccharides has been reported to be of limited accuracy in the presence of proteins (9). The naphthoresorcinol test for hexuronic acids was

TABLE II

Elemental analysis of stone matrix

Mean results from five pools of calculi ( \pm S.D.); corrected for inorganic ash content

\begin{tabular}{|c|c|c|c|c|}
\hline & Carbon & Hydrogen & Nitrogen & $\begin{array}{c}\begin{array}{c}\text { Conjugated } \\
\text { sulfate sulphur }\end{array} \\
\end{array}$ \\
\hline $\begin{array}{l}\text { Total matrix } \\
\mathrm{NaCl} \text { soluble portion } \\
\mathrm{NaCl} \text { insoluble residue }\end{array}$ & $\begin{array}{l}57.24( \pm 1.22) \\
58.62( \pm 0.81) \\
56.80( \pm 3.61)\end{array}$ & $\begin{array}{l}7.03( \pm 0.13) \\
7.40( \pm 0.84) \\
7.21( \pm 0.46)\end{array}$ & $\begin{array}{l}10.32( \pm 0.53) \\
10.65( \pm 0.83) \\
10.32( \pm 0.48)\end{array}$ & $\begin{array}{l}0.98( \pm 0.29) \\
0.78( \pm 0.17) \\
0.78( \pm 0.26)\end{array}$ \\
\hline
\end{tabular}


negative, but this test has been reported unsatisfactory for the determination of hexuronic acids in acid mucopolysaccharides (17). The carbazole reaction of Dische also gave a negative test for hexuronic acids. The sensitivity of this test was such that 0.05 to 0.1 per cent hexuronic acid content of the matrix would have been detected. The diphenylamine test for "sialic acid" as described by Winzler (7) and also by Anderson and Maclagan (8) was negative for stone matrix, although control studies on Tamm and Horsfall mucoprotein (18) and on urinary mucoprotein isolated by the Anderson-Maclagan technique were strongly positive.

Both the Elson-Morgan ( 7 ) and the DischeBorenfreund (19) reactions gave a positive test for hexosamine. The hexosamine content of total matrix from 5 pools of freshly recovered calculi averaged 14.0 per cent (range 11.8 to 16 per cent) by the Elson-Morgan reaction. The DischeBorenfreund reaction gave an average hexosamine content of 14.6 per cent for the same preparations. The agreement between these two methods is a further indication that neither hyaluronic nor chondroitin-sulfuric acids are present since these acid mucopolysaccharides produce marked discrepancies in the results obtained by the indole$\mathrm{HCl}$ technique as compared with the ElsonMorgan reaction.

Chromatographic study of carbohydrate and amino acid content. A 16-mg. sample of total matrix was hydrolyzed with $10 \mathrm{ml}$. of $6 \mathrm{~N} \mathrm{HCl}$ for 20 hours in a sealed tube at $100^{\circ} \mathrm{C}$. Twodimensional chromatograms with phenol and lutidine solvents were made on Whatman No. 1 filter paper according to the method described by Block, Durrum, and Zweig (20). The amino acids threonine and leucine (isoleucine) were present in largest concentration. Serine, glycine, tyrosine, and hexosamine were also identified. Arginine was thought to be present but was poorly separated from lysine, and two materials which stained poorly with ninhydrin could not be identified.

A 100-mg. sample of the total martix was hydrolyzed with $5 \mathrm{ml}$. of $\mathrm{N} \mathrm{H}_{2} \mathrm{SO}_{4}$ at $100 \mathrm{C}$. for 6 hours in a sealed vial. The hydrolysate was neutralized with $\mathrm{BaCO}_{3}$ and the supernatant subjected to two-dimensional chromatography utilizing 1-butanol:acetic acid: water $(4: 1: 5, \mathrm{v} / \mathrm{v})$ and 1-propanol: ethyl acetate: water $(7: 1: 2, \mathrm{v} / \mathrm{v})$ as solvents. The chromatogram was developed with 1 per cent alcoholic resorcinol in an equal volume of $0.2 \mathrm{~N} \mathrm{HCl}$. Galactose was definitely indicated as the predominant sugar but mannose was not detectable. One other pink staining material was present but could not be identified. It was determined not to be glucuronic acid, galacturonic acid, glucose, fructose, arabinose, maltose, lactose, raffinose or xylose.

\section{DISCUSSION}

Histochemically the calculus matrix is composed of a "neutral mucoprotein" which gives the positive PAS reaction and a "sulfated mucopolysaccharide" which is metachromatic with toluidine blue. Microscopically no distinct structural separation of the two substances has been demonstrable. Since the amount of metachromatic material varied considerably from one calculus to another, one would anticipate variations in the carbohydrate content of calculi in proportion to the variations in relative concentration of muco polysaccharide to mucoprotein. There has been little variation in the quantity of protein-bound hexose and hexosamine in 5 pools of freshly recovered matrix from calculi obtained from patients who were free of infection. Studies now being prepared for publication have demonstrated a wide range of variation in the total hexose plus hexosamine content of calculi which were permitted to dry at room temperature prior to decalcification, or which were recovered from patients with urinary tract infection. However, the quantity of hexose to hexosamine has remained at very near $1: 1$ ratio, or equimolar concentration, throughout the range of these variations in total carbohydrate content.

These preliminary studies offer insufficient evidence for conclusions as to the source of origin of the matrix. A number of carbohydrate-protein substances are present in normal and pathologic urine. Tamm and Horsfall (18) were the first to isolate and characterize the urinary mucoprotein which inhibits hemagglutination by certain viruses. The urinary mucoproteins recovered by Anderson, Lockey, and Maclagan (21) are in part composed of $\mathrm{T} \& \mathrm{H}$ mucoprotein. Blood group substances of types $A, B$, and $O(22)$ have been recovered from normal urine. Acidic mucopoly- 
saccharides which exhibit metachromasia, contain hexuronic acid, and have electrophoretic and chromatographic properties similar to chondroitin sulphate have been isolated from normal urine (23). Heparin may be a constituent of normal urine (24). Serum glycoproteins (MP-2) are present in relatively large concentration in normal urine (25), and orosomucoid (MP-1) has been demonstrated in the urine of children with the nephrotic syndrome by Popenoe (26). Hamerman, Reife, and Bartz (27) have demonstrated a correlation between the serum and urinary levels of protein-bound hexosamine and hexose in several diseases. The gonadotropic hormones are also mucoproteins which occur in the urine (28). Many bacteria and fungi produce polysaccarides containing aminosugars (29), and these substances are undoubtedly present in the urine of patients with pyelonephritis due to Proteus vulgaris, B. coli, Staphylococcus aureus, and other polysaccharide producing organisms.

None of the above mucosubstances appear to be closely related to the material recovered from urinary calculi. Meyer, Linker, Davidson, and Weissmann (30) have found the major polysaccharide component of bovine cornea to be a sulphated polysaccharide which does not contain uronic acid, and for which they have proposed the name keratosulfate. It is composed of equimolar quantities of glucosamine, acetyl, galactose, and sulfate. Two somewhat similar acidic substances which are metachromatic and which contain no uronic acids have been found in rabbit and human connective tissues by Consden and Bird (31). If one permits allowances for some loss of ester sulphate, then a polysaccharide of the above composition conjugated with a protein moiety in the ratio of approximately 34 per cent polysaccharide to 66 per cent protein would result in a molecule very similar to that of stone matrix. The future characterization of these mucosubstances must inevitably lead to the identification and the source of origin of the organic matrix of urinary calculi.

\section{SUMMARY}

The organic matrix is evenly distributed from the center to the surface of all calcigerous urinary calculi, and quantitatively comprises approximately 2.5 per cent of the weight of each calculus. Mi- croscopically the matrix appears as a mixture of amorphous and fibrillar forms which are closely related in elemental composition. However, wide variations in carbohydrate and amino acid content may occur within the framework of this elemental composition and the present studies offer no conclusive evidence that the amorphous and fibrillar forms of the matrix are identical substances. Histochemically matrix is composed of a combination of mucoprotein (PAS positive) and mucopolysaccharide (metachromatic), which have not been separated or identified by preliminary chemical analyses.

Galactose and hexosamine in approximately equimolar concentration form the major components of the carbohydrate moiety of stone matrix. This accounts for approximately onethird of the matrix material. If all conjugated sulphate sulfur is present in the carbohydrate moiety then this portion of the matrix contains between 9 and 14 per cent sulphate. The presence of metachromasia is considered to indicate that a part or all of this sulphate may exist in the ester form.

The protein or peptide portion of the molecule contains threonine, leucine, serine, glycine, lysine, arginine, and tyrosine with other components that have not been identified. The protein moiety accounts for approximately two-thirds of the matrix.

\section{ACKNOWLEDGMENT}

The authors are indebted to J. S. King, Jr. Ph.D. Bristol, Tennessee for technical advice and assistance, and to Clark Microanalytical Laboratory, Urbana, Ill for confirmatory analysis of the elemental composition of calculous matrix.

\section{REFERENCES}

1. LaTowsky, L. W., Qualitative chemical analysis of urinary calculi. J. Urol., 1943, 49, 720.

2. Operating Instruction for the Todd Spectranal, Bulletin of the Todd Scientific Co., Springfield, Pa., 1953.

3. Lillie, R. D., Histopathologic Technic and Practical Histochemistry, New York, The Blakiston Company, Inc., 1954, p. 114.

4. Holmgren, H., Studien über Verbreitung und Bedeutung der chromotropen Substanz. Ztschr. f. mikr.anat. Forsch., 1940, 47, 489.

5. Sulkin, N. M., Histochemical studies on mucoproteins in nerve cells of the dog. J. Biophysical and Biochemical Cytology, 1955, 1, 459.

6. Dische, Z., New color reactions for determination of sugars in polysaccharides in Methods of Biochemi- 
cal Analysis, Glick, D., Ed., New York, Interscience Publishers, Inc., 1955, vol. II, p. 313.

7. Winzler, R. J., Determination of serum glycoproteins in Methods of Biochemical Analysis, Glick, D., Ed., New York, Interscience Publishers, Inc., 1955, vol. II, p. 279.

8. Anderson, A. J., and Maclagan, N. F., The isolation and estimation of urinary mucoproteins. Biochem. J. (Lond.), 1955, 59, 638.

9. Di Ferrante, N., Quantitative colorimetric assay of acid mucopolysaccharides. J. Biol. Chem., 1954, 209, 579.

10. Cheronis, N. D., Tests for functional groups in Technique of Organic Chemistry, Weissberger, A., Ed., New York, Interscience Publishers, 1954, vol. VI, p. 467.

11. Deichmann, W., The quantitative estimation of glucuronates in urine. J. Lab. \& Clin. Med., 1943, 28, 770.

12. Dische, Z., A new specific color reaction of hexuronic acids. J. Biol. Chem., 1947, 167, 189.

13. Niederl, J. B., and Niederl, V., Micromethods of Quantitative Organic Analysis, New York, J. Wiley \& Sons, Inc., 1942, 2nd ed.

14. Hawk, P. B., Oser, B. L., and Summerson, W. H., Practical Physiological Chemistry, Philadelphia, The Blakiston Co., 1951, 12th ed., p. 886.

15. Howard, J. E., Some current concepts on the mechanism of calcification. J. Bone \& Joint Surg., 1951, 33-A, 801.

16. Simmons, J. S., and Gentzkow, C. J., Medical and Public Health Laboratory Methods, Philadelphia, Lea \& Febiger, 1955, p. 370.

17. Meyer, K., Block, H. S., and Chaffee, E., The colorimetric determination of uronic acids. Federation Proc., 1942, 1, 125.

18. Tamm, I., and Horsfall, F. L., Jr., Characterization and separation of an inhibitor of viral hemagglutination present in urine. Proc. Soc. Exper. Biol. \& Med., 1950, 74, 108.

19. Dische, Z., and Borenfreund, E., A spectrophotometric method for the microdetermination of hexosamines. J. Biol. Chem., 1950, 184, 517.
20. Block, R. J., Durrum, E. L., and Zweig, G., A Manual of Paper Chromatography and Paper Electrophoresis, 2nd ed., New York, Academic Press, Inc., 1955.

21. Anderson, A. J., Lockey, E., and Maclagan, N. F., Some biological properties of the urinary mucoproteins. Proc. Biochem. Soc., Biochem. J., 1955, 60 , xli.

22. Hamerman, D., Reife, A., Bartz, K. W., and Hatch, F. T., The nature of high molecular weight carbohydrate-protein constituents in normal human urine. Report No. 154, Army Medical Nutrition Lab., Denver, Colo., Feb. 24, 1955.

23. Kerby, G. P., The occurrence of acid mucopolysaccharides in human leukocytes and urine. J. Clin. Invest., 1955, 34, 1738.

24. Astrup, P., On the determination of heparin in blood plasma and urine. Acta pharmacol. et toxicol., 1947, 3, 165.

25. Boyce, W. H., Garvey, F. K., and Norfleet, C. M., Jr., Proteins and other biocolloids of urine in health and in calculous disease. I. Electrophoretic studies at $\mathrm{pH} 4.5$ and 8.6 of those components soluble in molar sodium chloride. J. Clin. Invest., 1954, 33, 1287.

26. Popenoe, E. A., Characterization of a glycoprotein in the urine of patients with proteinuria. J. Biol. Chem., 1955, 217, 61.

27. Hamerman, D., Reife, A., and Bartz, K. W., Levels of hexosamine and hexoses in plasma and urine in patients with certain disease or injuries. J. Lab. \& Clin. Med., In press.

28. Gurin, S., Bachman, C., and Wilson, D. W., The gonadotropic hormone of urine of pregnancy. II. Chemical studies of preparations having high biological activity. J. Biol. Chem., 1940, 133, 467.

29. Kent, P. W., and Whitehouse, M. W., Biochemistry of the Aminosugars. New York, Academic Press, Inc., 1955, Chap. 7, p. 133.

30. Meyer, K., Linker, A., Davidson, E. A., and Weissmann, B., The mucopolysaccharides of bovine cornea. J. Biol. Chem., 1953, 205, 611.

31. Consden, R., and Bird, R., The carbohydrate of connective tissues. Nature, 1954, 173, 996. 